\title{
Bio-based polyurethane coating synthesized from modified castor oil - applicable in base coat of automobile paint
}

\author{
D Mohanty', MK Kanny', S Mohanty², SK Nayak²
}

\author{
${ }^{1}$ Composite Research Group, Department of Mechanical Engineering, Steve biko Campus, Durban University of Technology, Durban, \\ Kwazulunatal, South Africa, 4001

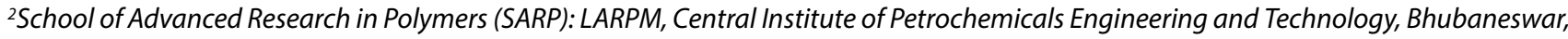 \\ Odisha, India, 751024 \\ Email: debasmita.mohanty87@gmail.com
}

\begin{abstract}
The current study reports the epoxidation of castor oil (CO) by using hydrogen peroxide as catalyst and formic acid as oxidizing agent. Subsequently bio based polyurethane based base coat was synthesized by using epoxidised castor oil (ECO) as polyol, Isophorone diisocyanate (IPDI) as curing agent and dibutylin dilaurate (DBTDL) as catalyst. The paint formulation with $\mathrm{OH}$ :NCO ratio 1:1.2 was optimized. An independent study was carried out employing the mechanical test like cross-cut tape test was carried out to evaluate the paint properties. Morphological and structural studies like FTIR, SEM, HNMR were carried out with the paint formulation. Thermal property studies like TGA, DSC were carried out with the paint. Gloss, weather resistance of the paint was evaluated.
\end{abstract}

Key words: Epoxidation, Castor oil, Polyurethane, Base coat, Automobile paint, Epoxidised castor oil

\section{Introduction}

Automobile paint is now one of the most versatile research topics. Numerous researches are now going on this particular topic. Automobile paints normally use petro-based feedstock as the raw material during synthesis. However, with the current demand in eco-friendly derivatives, there has been increased surge in reducing the dependence of petro based feedstock in coating industry while moving towards alternative resources. In general the automobile paint is applied in four layers i.e., E-coat, primer the second layer which is responsible for adhesion and levelling of the paint, base coat as the third layer which has colour pigments and most important properties of paint, and the top most layer is clear coat, a glossy transparent layer works as a protective layer of paint and it also gives gloss to the paint. The base coat and clear coat of automobile body is normally polyurethane (PU) based. In recent research studies, vegetable oils are considered as one of the most desirable component in chemical industries. These natural products have triglycerides and a very high number of unsaturated fatty acids which leads their preference over the nonrenewable resources. ${ }^{1}$ These have significant properties like high viscosity index, high lubrication capacity, better flash point, low volatility $\&$ high molecular weight. ${ }^{2}$ The most common vegetable oils used in chemical industry are, castor oil, soybean oil, sunflower oil etc. Among all the vegetable oils castor oil is the most abundantly available vegetable oil, with Brazil, India and China being the largest producers. ${ }^{3}$ Some edible plant oils like coconut oil, peanut oil, mustard oil can be used as raw material but it can affect the food chain. Vegetable oils like palm oil, soybean oil, castor oil etc. are the most suitable materials in bio-based industries. Castor oil is the mostly preferred vegetable oil, because of its low production cost and high productivity. ${ }^{4}$ Castor oil is yellow, odorless and non-volatile oil which is soluble in most of the solvents having higher viscosity and hygroscopicity. It has a higher $-\mathrm{OH}$ value which makes it more reactive for synthesis process and it also can be stored for longer time while kept in air tight condition. ${ }^{5}$ It consists of reicinoleic acid which constitutes between $86 \%$ and $92 \%$ of the triglycerides. ${ }^{5}$ In spite of all the advantages castor oil-based polyols also have some short comings like lower thermal resistivity and lower oxidative properties due to presence of unsaturated carbon-carbon double bond. To overcome this drawback, castor oil modification is preferred which converts the carbon-carbon double bond into oxirane rings. There is a number of modification process such as epoxidation followed by oxirane ringopening, hydroformylation followed by hydrogenation, ozonolysis and transesterification. Among all the processes, epoxidation is one of the most used processes. The epoxidised vegetable oils can be directly used as resin in paint and coating industry. In chemical industries, the epoxidation process is normally carried out with the help of either formic acid or acetic acid. In some cases $\gamma$-alumina is also used. The process followed is known as peroxide method, as hydrogen peroxide is used as the catalyst. Epoxidation of double bond of vegetable oils, followed by oxirane ring opening is one of the most commonly used methods to increase the hydroxyl groups on the carbon-carbon double bond. ${ }^{6}$ Compare to other vegetable oils, it has a good shelf life. ${ }^{7}$ Modified castor oil is mostly preferred for synthesis of branched polyurethane structure. ${ }^{8}$ Automobile paints are in general polyurethane based which consists of urethane linkage. Urethane linkage is a polymerization of polyol and isocyanate. The characteristics of polyurethane based paint in general depend on the type of polyol used.

By using modified castor oil as the polyol for paint synthesis, can result into a scratch resistive, oil resistive and thermally stable biobased paint due to the presence of reactive hydroxyl groups along with the oxirane rings present in the epoxidized castor oil. ${ }^{9}$ 


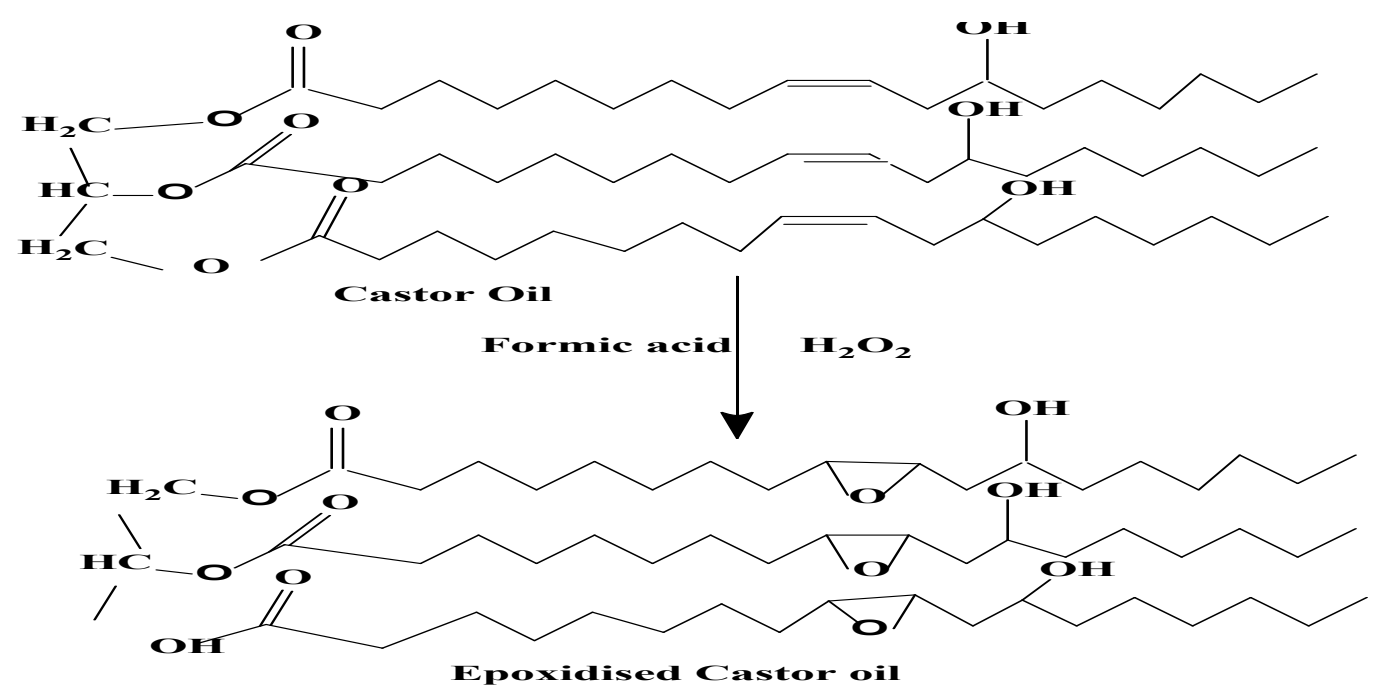

Scheme 1: Epoxidation of CO

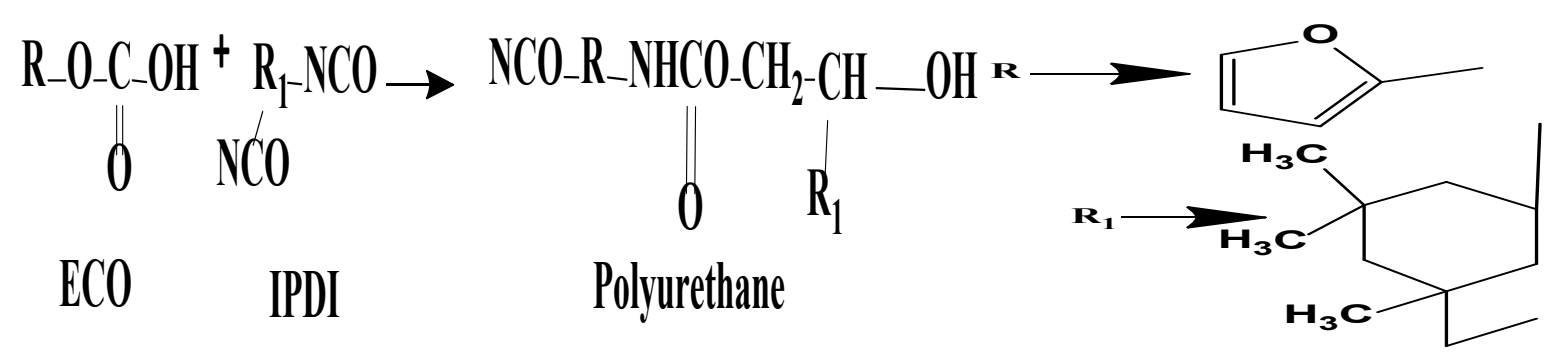

Scheme 2: Polyurethane synthesis

\section{Experimental}

\subsection{Materials and methods}

CO (Iodine Value 85-90, OH value 170, Refractive index 1.47581.1498),AR grade xylene and formic acid (85\%) purchased from $\mathrm{M} / \mathrm{s}$. Merck chemicals Pvt. Ltd, Mumbai. Isophorone diisocyanate (IPDI) from M/s. Sigma Aldrich, Bangaluru. Dibutyltin dilaurate (DBTDL) from M/s TCI chemicals Pvt. Ltd. Tokyo. 30\% Hydrogen peroxide $\left(\mathrm{H}_{2} \mathrm{O}_{2}\right)$ were procured from M/s NICE Pvt. Ltd. Kochi. Sodium bicarbonate $\left(\mathrm{NaHCO}_{3}\right)$ was procured from $\mathrm{M} / \mathrm{s}$ CDH Pvt. Ltd. New Delhi. 20\% Ammonia solution $\left(\mathrm{NH}_{4} \mathrm{OH}\right)$ was procured from M/s Research-lab fine chem. Industries, Mumbai.

\subsection{Synthesis of PU based coating}

Epoxidation of castor oil has been done in line with the following procedure.CO was taken in a three-necked round bottom glass flask dipped in oil bath equipped with nitrogen atmosphere and condenser. The solution was stirred in a magnetic stirrer at $45^{\circ} \mathrm{C}$. Hydrogen peroxide $\left(\mathrm{H}_{2} \mathrm{O}_{2}\right)$ was added drop wise in 1.8:1 molar ratio of $\mathrm{H}_{2} \mathrm{O}_{2}$ :CO.Then formic acid was added at molar ratio $1: 1$ with $\mathrm{H}_{2} \mathrm{O}_{2}$. The reaction was continued for 5 hours followed by addition of $\mathrm{NH}_{4} \mathrm{OH}$ and $\mathrm{NaHCO}_{3}$ to the reaction mixture to neutralize the acidity. The reaction mixture was then washed twice with ethanol and finally purified in a rotary evaporator. Subsequently, ECO was dissolved in xylene at a ratio of ECO:xylene of 1:0.5. After that IPDI was added to it at variable $\mathrm{OH}: \mathrm{NCO}$ ratio $1: 1,1: 1.1,1: 1.2$ and $1: 1.3$. The reaction temperature was maintained at $45^{\circ} \mathrm{C}$ and the synthesis was carried out for 2 hours. The whole process was undertaken in nitrogen atmosphere, connected with condenser. The products are $\mathrm{PU}_{1}, \mathrm{PU}_{2}, \mathrm{PU}_{3}$ and $\mathrm{PU}_{4}$ respectively according to the $\mathrm{OH}$ :NCO ratio. Among the PU synthesized, the $\mathrm{OH}: \mathrm{NCO}$ ratio of 1:1.2 i.e., $\mathrm{PU}_{3}$ was optimized based on the properties i.e. scratch resistance and adhesion.

\subsection{Characterization}

\subsubsection{Cross-cut tape test}

The adhesion and scratch resistance properties of coatings were evaluated using cross-cut Tape test in accordance with ASTM D 3359-97. A cross cutter was used to draw 11 lines of 30mm length within $10 \mathrm{~mm}$ width at equal distance on the coating surface applied on mild steel substrate. The same cross cutter was used to draw another 11 lines in similar manner in cross sectional way. Then an adhesion tape of $25 \mathrm{~mm}$ width, semitransparent and pressure sensitive tape (3M scotch tape) was pressed on the cutting surface for 1 minute and then peeled forcefully at $180^{\circ}$ angle to observe the scratch resistance and adhesion properties of paint. The adhesion value was calculated using the following formula:-

Adhesion $=\left(\frac{\text { Number of squares attached to the adhesion tape }}{\text { Total number of squres on the coated substrate }} \times 100\right) \%$

2.3.2 Fourier Transform Infrared analysis (FTIR) and Proton Nuclear Magnetic Resonance ( $\left.{ }^{1} H N M R\right)$ Spectroscopy

FTIR analysis of APTES functionalized ECO and the PU paint were carried out using Nicolet 6700 spectrometer (M/s Thermo Scientific, USA) at a range of $4000-400 \mathrm{~cm}^{-1} .{ }^{1} \mathrm{HNMR}$ spectra of polyurethane samples were recorded using a JEOL DELTA2 500 


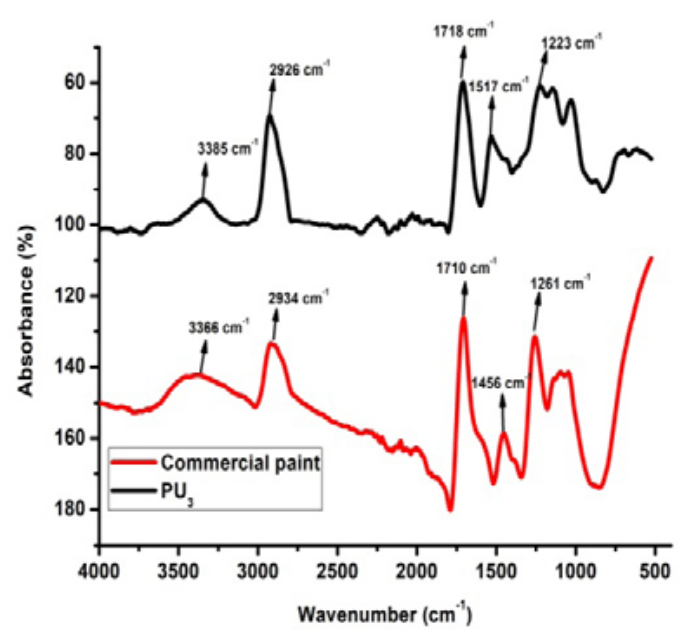

Figure 1: FTIR spectra of $\mathrm{PU}_{3}$

MHz FX-1000spectrometer (INSTROM) at $500 \mathrm{MHz}$ employing deuterated chloroform $\left(\mathrm{CDCl}_{3}\right)$.

\subsubsection{Scanning Electron Microscopy (SEM)}

SEM analysis of the coating mounted on a carbon sticker were conducted using EVO MA15microscope (M/s Carl Zeiss SMT, Germany) having acceleration voltage of $0.2-30 \mathrm{kV}$ and magnification $5-1,000 \mathrm{KX}$. Prior to analysis, the samples were sputter coated with $\mathrm{Au} / \mathrm{Pd}$ mixture.

\subsubsection{Gloss Test \& Weather Resistance Test}

Gloss study was carried out with a digital gloss meter (SFM-115, M/s S.C.Dey \& Co., Kolkata, India) at $45^{\circ}$ angle. Weather resistance test was carried out in QUV/SE (M/s Q-Lab Corporation, USA) instrument in presence of UV environment for 1200 hours and gloss was taken as the parameter to study the change in properties.

\subsubsection{Thermogravimetric Analysis (TGA) and Differential Scanning Calorimetry (DSC) Analysis}

TGA analysis of PU coating was carried out using TGA Q50 (M/s TA Instruments, USA) as per ASTM E 1868. The samples were scanned from $30-600^{\circ} \mathrm{C}$ at a heating rate of $10^{\circ} \mathrm{C} / \mathrm{min}$. Corresponding initial and final degradation temperature and \% char was recorded.DSC analysis was carried out in DSC-8000 (M/s. PerkinElmer Pvt. Ltd. USA). The sample was scanned from -50 to $250^{\circ} \mathrm{C}$ at a heating rate of $10^{\circ} \mathrm{C} / \mathrm{min}$.

\subsubsection{Oil Resistance Test}

The paint of the paint formulations coated over steel panels coated with the base coat was examined for resistance to petrol, diesel and engine oil respectively. The coated panels dipped in petrol, diesel and engine oil were kept for 8 hours at room temperature and $100^{\circ} \mathrm{C}$ for engine oil. After 8 hours the panels were removed from the liquids, washed and dried. Then the coating on the panels was studied to examine blister, softening or peeling if any.

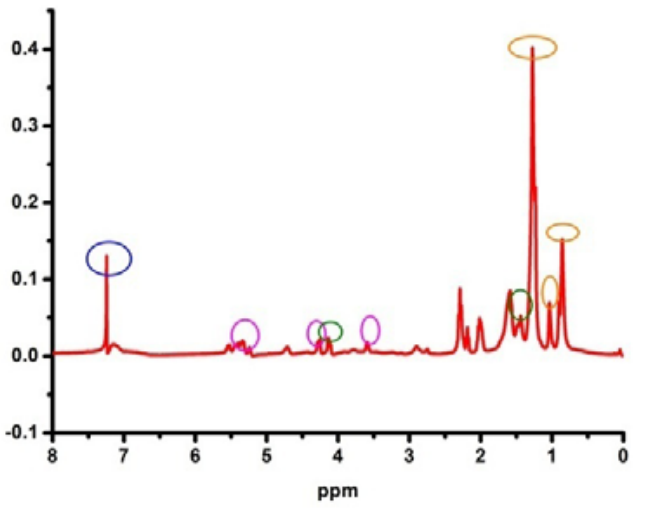

Figure 2: HNMR spectra of $\mathrm{PU}_{3}$

Table 1: Adhesion \% of samples

\begin{tabular}{lc}
\hline Sample Name & Adhesion \% \\
\hline $\mathrm{PU}_{1}$ & 46 \\
$\mathrm{PU}_{2}$ & 52 \\
$\mathrm{PU}_{3}$ & 66 \\
$\mathrm{PU}_{4}$ & 58 \\
\hline
\end{tabular}

\section{Results and discussion}

\subsection{Cross-cut tape test}

From the cross-cut tape test it was studied that the adhesion $\%$ of the paint sample with $\mathrm{OH}: \mathrm{NCO}$ ratio $1: 1$ is only $46 \%$. This increased to $52 \%$ when the $\mathrm{OH}: \mathrm{NCO}$ ratio was taken to be $1: 1.1$. By further increasing the $\mathrm{OH}: \mathrm{NCO}$ ratio to $1: 1.2$ the adhesion $\%$ of the paint sample increased to $66 \%$. But when the $\mathrm{OH}: \mathrm{NCO}$ ratio increased to $1: 1.3$ the adhesion $\%$ decreased to $58 \%$ due to brittleness of the paint sample. So the paint formulation with $\mathrm{OH}$ :NCO ratio 1:1.2 was optimized to be the best parameter for the paint synthesis.

\subsection{FTIR and HNMR}

From the above fig. it was studied that the FTIR spectra of $\mathrm{PU}_{3}$ and commercial base coat observed the - $\mathrm{NH}$ stretching at 3385 $\mathrm{cm}^{-1}$ and $3366 \mathrm{~cm}^{-1}$, while $-\mathrm{CH}$ stretching at 2926 and $2934 \mathrm{~cm}^{-1}$. The spectra 1718 and $1710 \mathrm{~cm}^{-1}$ revealed the $\mathrm{C}=\mathrm{O}$ and the spectra 1517 and $1456 \mathrm{~cm}^{-1}$ revealed the -CH bond. At 1223 and $1261 \mathrm{~cm}^{-1}$ the spectra showed $-\mathrm{CN}$ stretching. These spectra confirmed the formation of polyurethane and the base material for commercial base coat is PU. Similar results were observed by Asefnejadet.al. ${ }^{10}$ The 1H NMR spectra of $\mathrm{PU}_{3}$ is depicted in Fig.2. It is observed that the chemical shift $\delta$ value corresponding to $5.33,4.25$, and $3.57 \mathrm{ppm}$, is primarily due to $-\mathrm{CH}, \mathrm{CH}_{2}$ allyl, and $-\mathrm{CH}_{2}-$ vinyl, respectively. The peaks at 3.57 and 4.25 ppm correspond to $-\mathrm{CH}_{2}$ adjacent to secondary $\mathrm{C}$ and $\mathrm{CH}_{2}-\mathrm{O}-\mathrm{C}=\mathrm{O}-$, respectively. The peak at $7.22 \mathrm{ppm}$ reveals the presence of $\mathrm{CDCl}_{3} .1 .28,1.02$ and 0.85 ppm indicate the methyl proton group. Two small peaks at 4.09 and $1.42 \mathrm{ppm}$ attributes to the butelene groups linking to the carbonate group. ${ }^{11}$ 

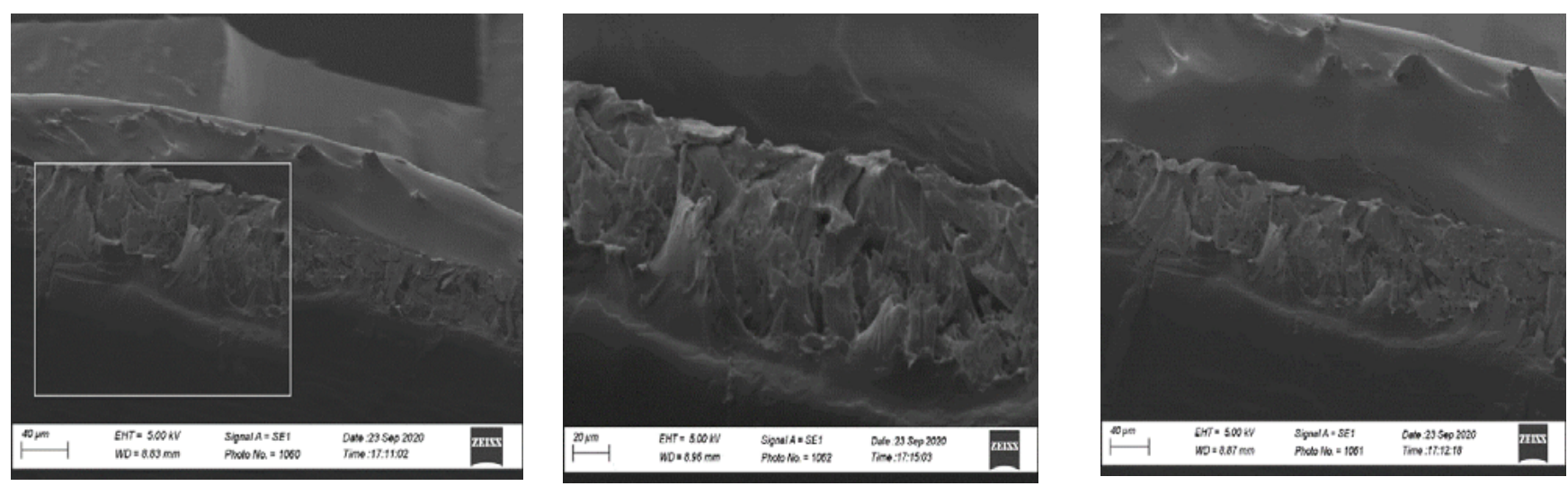

Figure 3: Cross-sectional SEM micrographs of $\mathrm{PU}_{3}$

\subsection{SEM}

SEM micrographs of the cross-section of $\mathrm{PU}_{3}$ is enumerated in fig 3 , it is evident that neat PU paint has very less agglomeration present and the homogeneity of the film was good clearly showing the hard segment and soft segment as indicated in the above figure. ${ }^{12}$

\subsection{Gloss and weather resistance test}

Gloss of the polyurethane paint was first observed to be 25.3 in Gloss meter. Then the paint sample was put in a weather meter exposed to UV-rays and extreme environmental conditions for 1200 hours. Then the gloss was observed to be 13.4. The gloss intact was found to be $53 \%$, which is near about the gloss intact \% for commercial base coat after weather meter treatment.

\subsection{TGA and DSC}

The DTG thermo gram of polyurethane enumerated about the initial and final degradation temperature along with phase changes observed in the paint formulation. The initial degradation temperature was found to be $271^{\circ} \mathrm{C}, 50 \%$ degradation was observed at $340^{\circ} \mathrm{C}$ and final degradation temperature of the paint formulation was studied to be at $490^{\circ} \mathrm{C}$. For commercial base coat initial degradation it was found to be at 303,376 and $545^{\circ} \mathrm{C}$ respectively. In case of commercial base coat the char yield was studied to be $55 \%$ due to presence of numerous additives and plasticizers. The char yield was found to be $0.29 \%$ in $\mathrm{PU}_{3}$ which indicates complete polymerization of the synthesized polymer. From the derivative weight vs. temperature graph it was studied that degradation of hard segment of polyurethane occurred at $307^{\circ} \mathrm{C}$ and degradation of soft segment occurred at $355^{\circ} \mathrm{C}$ and in commercial base coat the degradation of urethane linkage was only observed at $393^{\circ} \mathrm{C} .{ }^{13}$ To investigate the crystalline phases in polyurethane coating that are formed by the hard segments and soft segments, DSC analysis has been used. The first heating scans of the polyurethane show glass transition of soft segment in the temperature of about $-54^{\circ} \mathrm{C}$. However, a relaxation transition could not clearly be observed at high chain extender contents. This may be due to that the crosslinking of the hard segments obscures the polyol segment's motion, which leads to having less soft segments with ordered structures or

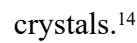

\subsection{Oil resistance test}

When the paint sample was immersed in petrol for 8 hours, slight softening was observed, while a little bit of peeling was studied when immersed in diesel. But in engine oil both softening and peeling were observed to some extent. This proves that the paint can withstand the oils as no change was observed after 8 hours of immersion in the oils.

\section{Conclusion}

In this study, eco-friendly base coat of automobile paint was synthesized using ECO as polyol, IPDI as curing agent and DBTDL as catalyst. It is observed that the base coat prepared from ECO exhibited very good thermal, mechanical, physicochemical
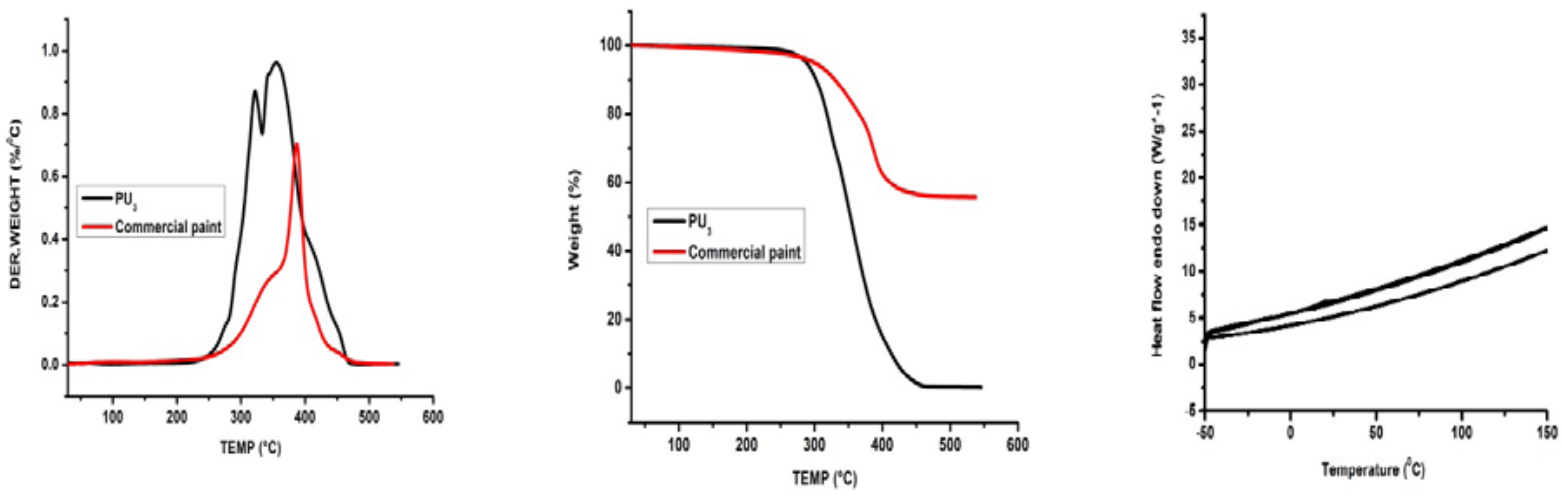

Figure 4: DTG Thermogram of $\mathrm{PU}_{3}$ and Commercial base coat 
and coating properties and can be comparable with the properties of commercial base coat. FTIR and HNMR studies confirmed the chemical bonds of the PU matrix and the base material for commercial paint to be PU. SEM studies revealed the formation of hard segment, soft segment in the PU matrix. The DTG thermo gram revealed the initial and final temperature of degradation corresponding to the phase changes exhibited in both PU matrix and commercial paint. Due to strong interfacial interaction and higher cross-linking density the PU matrix is considered as a suitable polymer for paint synthesis. Hence, it can be summarized that the base coat synthesized from ECO can be used as a promising alternative to petro based base coat in automobile paints.

\section{References}

1. S. Sinadinović-Fišer, M. Janković, and O. Borota, "Epoxidation of castor oil with peracetic acid formed in situ in the presence of an ion exchange resin," Chem. Eng. Process. Process Intensif., vol. 62, pp. 106-113, 2012, doi: 10.1016/j.cep.2012.08.005.

2. V. B. Borugadda and V. V. Goud, "Epoxidation of castor oil fatty acid methyl esters (COFAME) as a lubricant base stock using heterogeneous ion-exchange resin (IR-120) as a catalyst," Energy Procedia, vol. 54, no. 0361, pp. $75-84,2014$, doi: $10.1016 / \mathrm{j}$. egypro.2014.07.249.

3. Í. C. Rios et al., "Chemical modification of castor oil fatty acids (Ricinus communis) for biolubricant applications: An alternative for Brazil's green market," Ind. Crops Prod., vol. 145, no. July, p. 112000, 2020, doi: 10.1016/j.indcrop.2019.112000.

4. G. Torrentes-Espinoza, B. C. Miranda, J. Vega-Baudrit, and J. F. Mata-Segreda, "Castor oil (Ricinus communis) supercritical methanolysis," Energy, vol. 140, pp. 426-435, 2017, doi: 10.1016/j. energy.2017.08.122.

5. V. Scholz and J. N. da Silva, "Prospects and risks of the use of castor oil as a fuel," Biomass and Bioenergy, vol. 32, no. 2, pp. 95-100, 2008, doi: 10.1016/j.biombioe.2007.08.004.
6. A. Sardari, A. A. Sabbagh Alvani, and S. R. Ghaffarian, "Castor oil-derived water-based polyurethane coatings: Structure manipulation for property enhancement," Prog. Org. Coatings, vol. 133, no. April, pp. 198-205, 2019, doi: 10.1016/j.porgcoat.2019.04.030.

7. S. KUMAR, S. MOHANTY, and S. G, "Synthesis and Optimization of Epoxidized Castor Oil in the Presence of a Sulphonated Polystyrene Type Cation Exchange Resin Catalyst," pp. 70-72, 2015, doi: 10.15224/978-1-63248-075-0-74.

8. A. Shaik, K. Baidya, K. Nehete, and S. Shyamroy, "Synthesis and characterization of castor oil-based branched polyols from renewable resources and their polyurethane-urea coatings," J. Coatings Technol. Res., vol. 16, no. 2, pp. 387-400, 2019, doi: 10.1007/ s11998-018-0118-8.

9. V. K. Mishra and R. H. Patel, "Synthesis and characterization of flame retardant polyurethane: Effect of castor oil polyurethane on its properties," Polym. Degrad. Stab., vol. 175, p. 109132, 2020, doi: 10.1016/j.polymdegradstab.2020.109132.

10. A. Asefnejad, M. T. Khorasani, A. Behnamghader, B. Farsadzadeh, and S. Bonakdar, "Manufacturing of biodegradable polyurethane scaffolds based on polycaprolactone using a phase separation method: physical properties and in vitro assay.," Int. J. Nanomedicine, vol. 6 , no. November, pp. 2375-2384, 2011, doi: 10.2147/ijn.s15586.

11. S. C. Feifel and F. Lisdat, "Silica nanoparticles for the layer-by-layer assembly of fully electro-active cytochrome c multilayers," J. Nanobiotechnology, vol. 9, no. 1, p. 59, 2011, doi: 10.1186/1477-3155-9-59.

12. S. Sahoo, H. Kalita, S. Mohanty, and S. K. Nayak, "Synthesis of Vegetable Oil-Based Polyurethane: A Study on Curing Kinetics Behavior," Int. J. Chem. Kinet., vol. 48, no. 10, pp. 622-634, 2016, doi: $10.1002 /$ kin. 21020

13. V. Benin, B. Gardelle, and A. B. Morgan, "Heat release of polyurethanes containing potential flame retardants based on boron and phosphorus chemistries," Polym. Degrad. Stab., vol. 106, pp. 108-121, 2014, doi: 10.1016/j.polymdegradstab.2013.09.004.

14. P. Somdee, T. Lassú-Kuknyó, C. Kónya, T. Szabó, and K. Marossy, "Thermal analysis of polyurethane elastomers matrix with different chain extender contents for thermal conductive application," J. Therm. Anal. Calorim., vol. 138, no. 2, pp. 1003-1010, 2019, doi: 10.1007 / s10973-019-08183-y. 